\title{
A contrastação empírica de um modelo teórico sobre o movimento de corpos com massa variável como uma forma de promover discussões epistemológicas em aulas de Física
}

The empirical contrast of a theoretical model on movement of bodies with variable mass as a way to promote epistemological discussions in physics classes

\author{
Leonardo Albuquerque Heidemann ${ }^{* 1}$, Ricardo Robinson Campomanes ${ }^{2}$, Ives Solano Araujo \\ ${ }^{1}$ Universidade Federal do Rio Grande do Sul, Instituto de Física, Departamento de Física, Porto Alegre, RS, Brasil. \\ ${ }^{2}$ Universidade Federal de Mato Grosso, Instituto de Ciências Naturais, Humanas e Sociais, Sinop, MT, Brasil. \\ ${ }^{3}$ Universidade Federal do Rio Grande do Sul, Instituto de Física, Departamento de Física, Porto Alegre, RS, Brasil.
}

Recebido em 07 de maio de 2020. Revisado em 29 de outubro de 2020. Aceito em 03 de novembro de 2020.

\begin{abstract}
A incorporação de discussões sobre a natureza do conhecimento científico em atividades didáticas de Ciências é um elemento fundamental e bastante desafiador. Este artigo tem como objetivo apresentar a contrastação empírica de modelos teóricos, explorando o caso particular do movimento de corpos com massa variável, como forma de destacar o papel do processo de modelagem científica em uma situação experimental. Ao incorporar a influência de diferentes forças resistivas sobre esses corpos, como as forças de arrasto com o ar e de resistência ao rolamento, investigamos as implicações de se assumir determinadas idealizações nos modelos contrastados, explicitando o caráter representacional do conhecimento científico no desenvolvimento de investigações experimentais. Buscase assim expor um exemplo de situação com potencial para ser explorada por professores na superação de concepções epistemológicas ingênuas por parte dos estudantes. Além disso, a investigação realizada envolve o uso de recursos computacionais open-source na construção de soluções numéricas dos modelos teóricos e na coleta de dados experimentais, favorecendo o uso de tecnologias livres no ensino de Física. Quatro dos seis modelos teóricos contrastados empiricamente tiveram também suas soluções analíticas deduzidas e comparadas com suas respectivas soluções numéricas. Os resultados mostram que a escolha do melhor modelo teórico que representa os dados coletados envolve mais do que a análise da qualidade do ajuste dos modelos, pois demanda uma avaliação das hipóteses assumidas nos modelos teóricos e das decisões tomadas pelo pesquisador.

Palavras-chave: Modelos Teóricos, Modelagem Computacional, Contrastação Empírica, Sistemas de Massa Variável, Modelagem Científica, Epistemologia.
\end{abstract}

The incorporation of discussions about the nature of scientific knowledge in science teaching activities is a fundamental and quite challenging aspect. This paper aims to present an empirical contrast of theoretical models exploring the particular case of the movement of bodies with variable mass as a way to highlight the role of the scientific modeling process in an experimental situation. We investigate the implications of assuming certain idealizations in the contrasted models, explaining the representative character of scientific knowledge in the development of experimental investigations, incorporating the influence of different resistive forces on these bodies, such as air drag forces and rolling resistance. Thus, we seek to expose an example of a situation with the potential to be explored by teachers in overcoming naive epistemological conceptions by students. Also, the investigation involves the use of open-source computational resources in the construction of numerical solutions of theoretical models and the collection of experimental data, favoring the use of free technologies in physics teaching. Four of the six empirically contrasted theoretical models also had their analytical solutions deduced and compared with their respective numerical solutions. The results show that the choice of the best theoretical model that represents the collected data involves more than the analysis of the quality of the adjustment of the models because it demands an evaluation of the hypotheses assumed in the theoretical models and the decisions made by the researcher.

Keywords: Theoretical Models, Computational Modeling, Empirical Contrast, Variable Mass systems, Scientific Modeling, Epistemology.

\section{Introdução}

A área de pesquisa em ensino tem alertado, já há algum tempo, sobre a importância das aulas de Física serem

\footnotetext{
*Endereço de correspondência: leonardo.h@ufrgs.br
}

bem fundamentadas epistemologicamente, sob pena da própria ação didática contribuir para a formação de concepções inadequadas sobre o fazer científico. Pautados pelas ideias de importantes filósofos da ciência, recomenda-se que as atividades didáticas favoreçam a construção de uma concepção da Física como um corpo 
de conhecimento desenvolvido por pessoas criativas que, apoiadas em crenças, são também dirigidas por argumentos metafísicos [e.g., [1, 2]]. Aconselha-se, para isso, o destaque ao caráter essencialmente humano da ciência, e que os estudantes sejam defrontados com situações que demandem uma postura ativa na tomada de decisões ao longo do desenvolvimento de tais atividades.

Contudo, muitos professores foram formados em uma tradição na qual aspectos epistemológicos da ciência não são tratados de forma explícita em aulas de Física ou em que esses aspectos são debatidos apenas em momentos pontuais, como em disciplinas específicas sobre filosofia da ciência, geralmente concentradas nos últimos semestres dos cursos de graduação. Como consequência, os docentes costumam ter dificuldades para delinear aulas em que elementos associados à natureza da ciência e ao fazer científico sejam naturalmente mobilizados a partir das discussões sobre conteúdos de Física.

Um contexto oportuno para o desenvolvimento de discussões sobre a construção do conhecimento científico é o laboratório didático. Apesar disso, não são raras aulas experimentais alinhadas, implícita ou explicitamente, com ideias empiristas ingênuas que promovem, entre outras coisas, a concepção de que as teorias da Física surgem da observação neutra ou de que experimentos cruciais proporcionam a prova ou a refutação dessas teorias. Buscando outros caminhos, pesquisadores têm explorado a inserção de outros objetivos de ensino para aulas experimentais com foco no fomento de processos argumentativos [3]; desenvolvimento de habilidades metacognitivas [4] ou em discussões mais aprofundadas sobre o processo de medição experimental [5, 6].

Neste artigo, assume-se que a formação científica contemporânea precisa abordar, desde as disciplinas básicas, aspectos epistemológicos em suas atividades de ensino. É apresentada uma discussão que pode auxiliar professores de Física na promoção de debates sobre o caráter representacional dos modelos científicos, contribuindo para a superação de concepções ultrapassadas de ciência promovidas implícita ou explicitamente em sala de aula. Tem-se como objetivo destacar a importância do processo de contrastação empírica de um modelo teórico e como isso pode suscitar debates sobre o papel do processo de modelagem científica na construção dos conhecimentos da Física. Em particular, são discutidas, em um exemplo da Física, as implicações das idealizações consideradas em um modelo científico na adequação de suas predições a resultados experimentais.

Para se alcançar esse objetivo, explora-se uma situação em que é realizada a contrastação empírica de um modelo teórico que representa o movimento de um corpo com massa variável. Diferentemente de abordagens empiristas ingênuas, a experimentação didática é entendida como um recurso para se investigar o domínio de validade dos modelos científicos, e não para se descobrir, provar ou refutar leis da natureza. Baseados na Modelagem Didático-Científica [7, 8], articulação teórica construída a partir das ideias de Mario Bunge 9] e de Gerard Vergnaud [10], entende-se que os modelos teóricos da Física são representações simplificadas da realidade (e.g., modelo newtoniano de pêndulo simples, modelo clássico de gás ideal, modelo de corpo negro) construídas com base em teorias gerais (e.g., Mecânica Clássica, Termodinâmica, Mecânica Quântica). Portanto, diversas idealizações e aproximações são consideradas na construção das representações esquemáticas que dão origem aos modelos.

O modelo teórico de gás ideal clássico, por exemplo, pode ser construído a partir do uso da Mecânica Estatística e da Mecânica Clássica (teorias gerais) para representar um conjunto idealizado de partículas pontuais que interagem apenas por meio de colisões perfeitamente elásticas. Por isso, esse modelo só é adequado, por exemplo, para representar gases quando as dimensões das suas moléculas são desprezíveis quando comparadas com as distâncias percorridas por elas entre as colisões, que ocorrem em um intervalo de tempo muito menor do que o intervalo transcorrido entre essas colisões. Por isso, quanto mais alta a densidade de um gás, mais ele se afasta das condições assumidas no modelo teórico de gás ideal. Poderíamos nos perguntar: qual é o limite de densidade para que o modelo de gás ideal represente um gás específico com um determinado grau de precisão considerado satisfatório frente a um certo problema? Questões como essa poderiam ser avaliadas teórica e experimentalmente. Contrastar predições construídas com o modelo de gás ideal com evidências experimentais, possibilitando uma avaliação do domínio de validade desse modelo, pode ser, então, uma atividade de modelagem que suscita discussões sobre as simplificações da realidade consideradas e sobre os procedimentos realizados para que essas simplificações sejam respeitadas em condições experimentais.

Não está no escopo deste artigo discutir os pormenores do processo de modelagem científica, que podem ser consultados em [7], nem as particularidades desse processo em atividades experimentais, que foram expostas em [8]. Aos moldes do que é feito em [11, restringe-se aqui a, baseando-se na Modelagem Didático-Científica, discutir uma situação em que são debatidos aspectos da natureza da ciência a partir de elementos do processo de modelagem científica em uma atividade experimental. Além disso, assumindo que o fazer científico é uma ação coletiva, privilegia-se o uso de softwares livres (Tracker ${ }^{1}$ e Insight Maker ${ }^{2}$ que, por serem gratuitos e de código aberto, podem contribuir significativamente para aumentar a transparência e a verificabilidade dos resultados por parte da comunidade [12].

A seguinte situação-problema motivou a construção dos modelos teóricos explorados nesta investigação:

\footnotetext{
1 Disponível em: https://physlets.org/tracker/ Acesso em 09 de abril de 2020 .

2 Disponível em: https://insightmaker.com/ Acesso em 09 de abril de 2020 .
} 


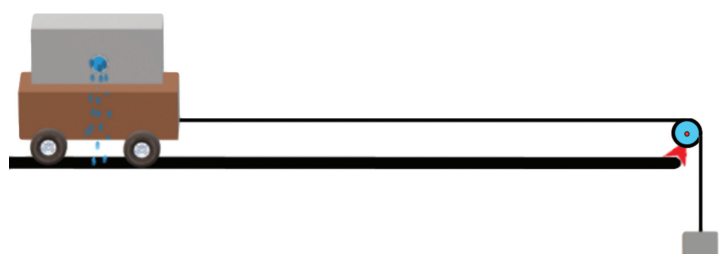

Figura 1: Representação da montagem experimental explorada. A água do recipiente acoplado ao carro escorre por meio de um furo presente em uma das suas paredes laterais.

Lançamento de foguetes, precipitação de areia sobre uma correia transportadora e caminhões-pipa regando longas extensões de terra são exemplos de situações que envolvem movimentos de corpos com massa variável. Como a perda de massa de um corpo influencia seu movimento? Optou-se por estudar um evento de laboratório que consiste em um pequeno carro se movendo em um trilho com um recipiente de água com um vazamento decorrente de um pequeno furo lateral, sendo puxado por uma fio tracionado por um pequeno objeto fixado na sua extremidade após passar por uma polia muito leve. A Figura 1 ilustra a montagem experimental.

A compreensão do evento criado em laboratório nos fornece subsídios para o entendimento das situações que motivaram essa investigação. Para se representar o evento construído, é necessário se responder algumas questões: No arranjo experimental explorado, que forças resistivas influenciam no movimento do carro? O que precisa ser considerado em um modelo teórico quando desejamos representar esse evento? Questões como essas dirigiram a construção e, consequentemente, a contrastação de diferentes modelos teóricos que orientaram a experimentação realizada.

$\mathrm{Na}$ próxima seção, são apresentadas considerações sobre os modelos teóricos que dirigiram a investigação realizada, destacando-se as simplificações da realidade assumidas. Em seguida, são destacados os procedimentos da contrastação empírica desses modelos conduzida na investigação, que envolve a construção de predições com o uso do software Insight Maker, e a coleta de dados com o software Tracker. São expostos, na seção seguinte, os resultados encontrados quando são avaliadas a pertinência de se considerar ou não alguns dos parâmetros propostos nos modelos construídos. Por fim, são apresentadas as conclusões e considerações finais.

\section{Modelo Teórico}

Para representar o evento alvo deste artigo, o movimento de um carro tracionado com massa variável construído em laboratório, foi tomada, como teoria geral, a Mecânica Newtoniana. Desse modo, é natural que se tenha que contabilizar as forças que agem sobre o sistema $S$, definido aqui como um sistema composto pelo carro, o recipiente que ele carrega e a água que permanece no recipiente. Destaca-se que $S$ não é um sistema fechado ${ }^{3}$ pois, além de a quantidade de água que permanece no recipiente varia com o passar do tempo, $S$ sofre forças decorrentes de interações com objetos externos ao sistema (e.g., força gravitacional).

A presente seção restringe-se a expor quais forças foram consideradas nas análises e como foram representadas. A partir disso, construíram-se diferentes modelos considerando, paulatinamente, algumas dessas forças. Esses modelos são detalhados na medida em que os resultados forem sendo apresentados na próxima seção. Quatro forças exercidas sobre $S$ foram avaliadas: força tensora $\vec{F}_{T}$ realizada pelo fio fixado no carro; força de arrasto com o ar $\vec{F}_{\text {arrasto }}$ (considerando força de arrasto viscoso $\vec{F}_{v}$ e força de arrasto inercial $\vec{F}_{i}$ ); força de resistência ao rolamento $\vec{F}_{\text {rol }}$; e força decorrente da vazão de água no recipiente $\vec{F}_{\vec{u}}$ (força de recud ${ }^{4}$ ).

A Figura 2 ilustra as forças que podem ser consideradas no modelo teórico investigado.

Em todos os modelos (contrastados na próxima seção) estão incluídas as forças $\vec{F}_{\vec{u}}$ e $\vec{F}_{T}$. No entanto, como será destacado, diferentes composições de $\vec{F}_{v}, \vec{F}_{i}$ e $\vec{F}_{\text {rol }}$ foram avaliadas. Passa-se a expor no que segue

(a)

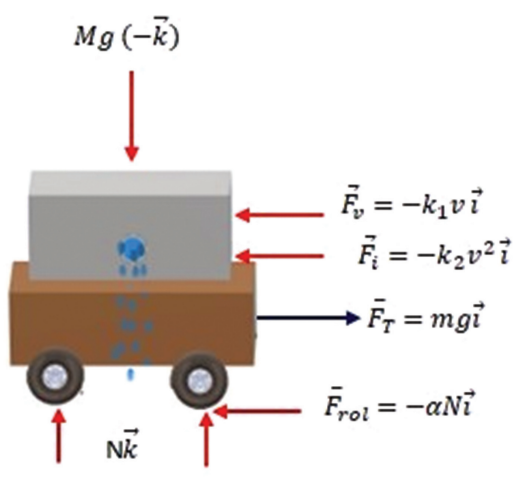

(b)

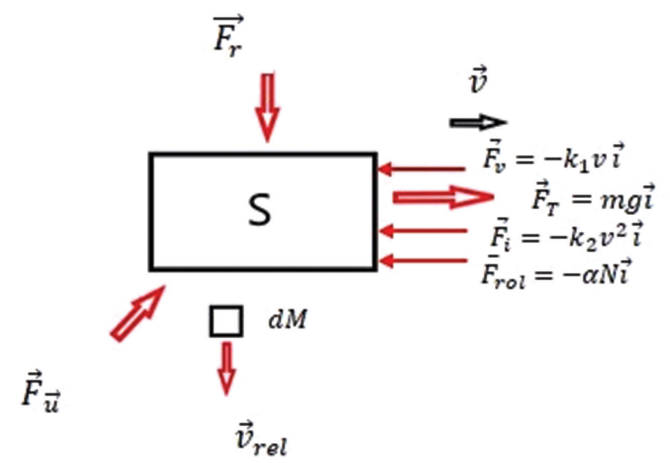

Figura 2: Representação das forças exercidas sobre o sistema. Na Figura 2(a), o sistema é representado por meio de uma vista lateral; na 2(b), de uma vista superior.

\footnotetext{
3 Segundo Nakayama [17, um sistema fechado (ou isolado) é um sistema em que a soma das forças externas sobre ele é zero.

${ }^{4}$ Essa força é decorrente da variação de momentum do sistema $S$. É em função dessa variação que ocorre, por exemplo, o efeito de recuo em um disparo com um revólver.
} 
como as idealizações consideradas nos modelos teóricos influenciam na forma como as forças são representadas.

A compreensão da força $\vec{F}_{\vec{u}}=\vec{F}_{\vec{u}}(t)$ demanda uma discussão sobre a sua natureza, sendo objeto de debates importantes na literatura desde bastante tempo [13 16]. Sem adentrar nessas discussões, adotam-se aqui as ideias de Nakayama [17, entendendo que, no experimento que se deseja representar, o sistema $S$ composto pelo carro e o recipiente com água, que possui massa instantânea $M=M(t)$, sofre uma força externa proporcional à taxa da variação temporal da sua massa $\dot{M}=R=R(t)$, dada por

$$
\vec{F}_{\vec{u}}=R \vec{u}
$$

onde $\vec{u}$ é a velocidade da água que vaza do recipiente em relação a um referencial inercial com origem no trilho. Como a velocidade de $S$ em relação ao trilho varia no evento investigado, $\vec{u}$ é uma função do tempo independentemente da vazão de água de $S$ ser considerada constante ou não, ou seja, $\vec{u}=\vec{u}(t)$. Podemos representar a velocidade $\vec{u}$ como a soma da velocidade $\vec{v}=\vec{v}(t)$ de $S$ em relação ao trilho com a velocidade relativa $\vec{v}_{r e l}=\vec{v}_{r e l}(t)$ da vazão de água de $S$ em relação a um referencial em $S$, ou seja

$$
\vec{u}=\vec{v}+\vec{v}_{r e l} .
$$

Assim sendo

$$
\vec{F}_{\vec{u}}=R\left(\vec{v}+\vec{v}_{r e l}\right) .
$$

Nas análises realizadas nesta investigação com o Insight Maker, considera-se a taxa de variação temporal de $R$ constante, ou seja, considera-se que a vazão no furo do recipiente varia linearmente no tempo. Portanto, assume-se que $R(t)=\theta-\beta t$, em que $\theta$ é a vazão inicial e $\beta$ é uma constante característica da variação dessa vazão. Definindo $R(0)=R_{0}$, ou seja, que a vazão inicial do recipiente é $R_{0}$, tem-se

$$
R(t)=R_{0}-\beta t
$$

Nos modelos construídos, admite-se também que $\vec{v}_{r e l}$ é perpendicular a $\vec{v}$, ou seja, considera-se que a direção instantânea da vazão da água ejetada do recipiente é ortogonal em relação ao carro no seu referencial de repouso. Desse modo, podemos reescrever a Equação 3 usando a Equação 2 do seguinte modo

$$
\vec{F}_{\vec{u}}=R v \vec{i}+R v_{r e l} \vec{j}
$$

sendo $\vec{i}$ e $\vec{j}$, respectivamente, vetores unitários na direção do movimento do carro e na direção perpendicular desse movimento. Desse modo, temos que a componente de $\vec{F}_{\vec{u}}$ na direção do movimento do carro é representada por

$$
\vec{F}_{\vec{u} x}(t)=R v \vec{i}=\left(R_{0}-\beta t\right) v \vec{i} .
$$

A componente de $\vec{F}_{\vec{u}}$ perpendicular à velocidade do carro se anula em $S$ ao ser somada com uma força $\vec{F}_{r}$, representada na Figura 2(b), que é a força de atrito exercida pelo trilho sobre o carro. Como a vazão do recipiente foi medida quando ele estava em repouso, é suposto também que a vazão do recipiente acelerado é a mesma de quando ele está em repouso.

Como o fio é aproximadamente inextensivel e a sua massa é muito menor que a massa $m$ do objeto preso em uma das suas extremidades, então o módulo da força $\vec{F}_{T}$ é aproximadamente igual ao módulo da força peso do objeto de massa $m$. Ao se aproximar a intensidade do campo gravitacional local $\vec{g}$ como constant 5 e igual à $9,79 \mathrm{~m} / \mathrm{s}^{2}$, assume-se que $\vec{F}_{T}$ é representada por

$$
\vec{F}_{T}=m g \vec{i} \text {. }
$$

Avaliaremos a influência de duas forças resistivas, quais sejam: resistência ao rolamento e arrasto com o ar. Assim como Silveira [19], considera-se $\vec{F}_{\text {rol }}=\vec{F}_{\text {rol }}(t)$ proporcional à $\vec{N}=\vec{N}(t)$, cujo módulo é igual à força peso do sistema $S$. Como é ilustrado na Figura 2(b), a força peso é representada neste artigo, considerando-se a intensidade do campo gravitacional local $g$ constante, como $M g(-\vec{k})$. Logo, considerando $\vec{N}=-M \vec{g}$, temos:

$$
\vec{F}_{\text {rol }}=-\alpha M g \vec{i}
$$

em que $\alpha$ é o coeficiente de resistência ao rolamento, que depende essencialmente da deformação da roda do carro [19, 20].

A força $\vec{F}_{\text {arrasto }}=\vec{F}_{\text {arrasto }}(t)$ é tratada como o somatório de $\vec{F}_{v}=\vec{F}_{v}(t)$, idealizada como proporcional à velocidade do carro, e $\vec{F}_{i}=\vec{F}_{i}(t)$, cujo módulo é assumido como proporcional ao quadrado da velocidade do carro. Tem-se, portanto

$$
\vec{F}_{\text {arrasto }}=\vec{F}_{v}+\vec{F}_{i}=-\left(k_{1} v+k_{2}|v| v\right) \vec{i},
$$

sendo $k_{1}$ e $k_{2}$, respectivamente, os coeficientes de arrasto viscoso e inercial. Esses coeficientes englobam os principais parâmetros que influenciam na intensidade da força de arrasto, como o formato do carro, e a densidade e a viscosidade do meio [21. Destaca-se que a força de arrasto não depende da massa do carro.

Definidas as idealizações e as forças consideradas, e usando a Segunda Lei de Newton, assumindo-se um referencial fixo no laboratório como um referencial inercial, podemos inferir a aceleração do carro. A adoção de um referencial inercial garante a validade do uso da Segunda Lei de Newton para suportar a construção de uma representação do movimento do carro. A resultante das forças $\vec{F}_{\text {res }}=\vec{F}_{\text {res }}(t)$ sobre $S$ é dada pela taxa de variação do momentum linear $\vec{p}=\vec{p}(t)=M(t) v(t)$ de $S$, ou seja

$$
\vec{F}_{\text {res }}=\dot{\vec{p}}=R \vec{v}+M \dot{\vec{v}}
$$

\footnotetext{
5 Usa-se aqui o valor medido no Campus do Vale da UFRGS usando os métodos de Bassel e de Kater. Para mais detalhes, veja [18].
} 
Segundo Nakayama [16, essa relação é válida para qualquer sistema aberto. Logo, a aceleração do carro $\ddot{\vec{x}}=\ddot{\vec{x}}(t)$ na direção que coincide com a direção do seu movimento é dada por

$$
\ddot{\vec{x}}=\left(\vec{F}_{r e s}-R \vec{v}\right) / M \text {. }
$$

Evidencia-se a partir da discussão exposta que o modelo teórico construído, assim como qualquer modelo científico, não é uma cópia fiel do evento que representa, mas sim uma representação simplificada que abarca apenas os aspectos chave do evento. A experimentação, como é tratada neste artigo, é entendida como um procedimento para se avaliar a adequação dessas idealizações para se representar um evento real.

No caso investigado neste artigo, o modelo teórico mais complexo que se pode construir, a partir do que foi exposto, é aquele que considera todas as forças propostas, ou seja, é aquele em que se considera a resultante das forças como o somatório de $\vec{F}_{\vec{u}}, \vec{F}_{T}, \vec{F}_{v}$, $\vec{F}_{i}$ e $\vec{F}_{\text {rol }}$. No entanto, é pertinente se questionar: Um modelo que considere mais variáveis e parâmetros sobre a realidade necessariamente possibilitará uma compreensão mais ampla do evento investigado? Considerando que a velocidade do carro no laboratório é pequena, o quão relevante é se considerar uma força de arrasto? E a força de resistência ao rolamento? Constatando-se que o trilho e as rodas do carro investigados são bastante rígidas, não seria oportuno desprezá-lo? Enfim, que idealizações são pertinentes quando se deseja representar o evento investigado neste artigo? A situação exposta aqui pode ser explorada por professores que buscam trazer ao debate em suas aulas de Física elementos sobre a natureza da ciência, refletindo sobre a tomada de decisão do cientista na escolha das idealizações e aproximações consideradas em seus modelos. Respostas a perguntas como essas demandam reflexões sobre o processo de modelagem científica, evidenciando o caráter representacional do conhecimento.

Outro elemento sobre o processo de modelagem científica e, portanto, sobre a natureza da ciência, a ser explorado por professores a partir da investigação apresentada, envolve os critérios para se avaliar a pertinência de se considerar ou não um determinado aspecto da realidade em um modelo teórico. Pode-se destacar que essa avaliação não se resume a uma análise da qualidade do ajuste das equações matemáticas englobadas nesse modelo a dados coletados experimentalmente, como foi destacado por Silveira e Ostermann 22 e Mayo [23]. Isso porque pouco ou nada adianta escolhermos uma função que se ajusta muito bem a um conjunto de dados se não soubermos explicar o significado físico dessa função.

Dessa perspectiva, não se pode imaginar que a avaliação da pertinência de se considerar todas as forças debatidas aqui demandará uma análise da qualidade do ajuste desses modelos aos dados coletados sobre o movimento do carro com massa variável. Certamente o modelo com mais parâmetros e variáveis implicará um melhor ajuste aos dados, como é destacado na Seção 6 deste artigo. Com o intuito de tornar a avaliação do domínio de validade dos modelos mais audaz, as predições contrastadas sobre o movimento do carro com massa variável foram construídas com os parâmetros $k_{1}, k_{2}$ e $\alpha$ inferidos do ajuste desses modelos usando $R=0$ (vazão nula) aos dados coletados do movimento do mesmo carro quando sua massa é constante (com o furo do recipiente fechado). Desse modo, presume-se que as constantes de proporcionalidade das forças de arrasto e de resistência ao rolamento não mudam pelo fato de o carro sofrer variação de massa. A primeira suposição, da invariância de $k_{1}$ e $k_{2}$ em função do escoamento de água no carro, foi tomada se assumindo que: $i$. a força de arrasto com o ar não depende da massa do carro; ii. a variação da área frontal do sistema em função do jato de água, que é incorporado ao evento com massa variável, é muito pequena; e iii. a velocidade máxima do carro é compatível com um número de Reynolds ${ }^{6}$ da ordem de $10^{3}$, faixa na qual o coeficiente de arrasto inercial é aproximadamente independente da velocidade. Já a hipótese de invariância de $\alpha$ é assumida porque as rodas do carro utilizado são bastante rígidas, permitindo se pressupor que o formato delas não variava significativamente quando submetida a variações de força da ordem de $4 \mathrm{~N}$, como as decorrentes da variação de massa do carro deste experimento. Com esse procedimento, não se está apenas usando métodos estatísticos para ajustar modelos teóricos ao conjunto de dados experimentais coletados, pois foram feitas predições usando dados previamente medidos e avaliadas as diferenças entre essas predições e evidências empíricas. A análise dessas diferenças é tomada como critério para a avaliação da pertinência de se considerar ou não as idealizações propostas. Na próxima seção, são detalhados os procedimentos de coleta de dados e de construção de predições.

\section{Coleta de Dados Empíricos: Videoanálise com o Software Tracker}

A coleta dos dados experimentais que fundamentou a contrastação dos modelos teóricos construídos foi realizada por meio da análise de vídeos com o uso do Tracker, um software open-source de videoanálise voltado para o ensino de Física [24, 25]. Valendo-se do fato de que vídeos são a apresentação sequencial de imagens (quadros), o aplicativo possibilita o registro da posição de um corpo em cada quadro de um vídeo e oferece ferramentas para analisar tais registros.

\footnotetext{
6 O número de Reynolds (ou coeficiente de Reynolds) é um valor adimensional proveniente da razão entre as forças de arrasto inercial e viscosa que agem sobre um corpo em movimento em relação a um fluido. Tal coeficiente proporciona um indicativo do tipo de escoamento do corpo no fluido: valores pequenos correspondem a escoamentos laminares; valores grandes, a escoamentos turbulentos 21 .
} 
Neste estudo, são analisados três vídeos 7 produzidos em um laboratório didático do Instituto de Física da Universidade Federal do Rio Grande do Sul. Nos dois primeiros, foi utilizado um pequeno carro de $500 \mathrm{~g}$, com rodas plásticas rígidas com $(25,40 \pm 0,01) \mathrm{mm}$ de diâmetro e $(6,35 \pm 0,01) \mathrm{mm}$ de espessura conectadas com rolamentos de esferas, no qual foi acoplado um recipiente plástico com água. A massa inicial do sistema composto pelo carro e o recipiente de água acoplado é de $M_{0}=(1,68 \pm 0,01) \mathrm{kg}$. Nesses vídeos, o carro translada em um trilho com aproximadamente $2,3 \mathrm{~m}$ tracionado por um fio de nylon com aproximadamente $2 \mathrm{~mm}$ de espessura. Esse fio passa por uma roldana muito leve e com pouco atrito 8 fixada no final do trilho, e é tensionado por um corpo preso a sua extremidade com massa $m=(0,0087 \pm 0,0001) \mathrm{kg}$. O recipiente plástica acoplado ao carro possui um orifício de aproximadamente 7,2 $\mathrm{mm}$, ao qual foi acoplada uma mangueira de silicone. No Vídeo 1, essa mangueira está fechada; no Vídeo 2, água vaza do recipiente por meio dela.

Em suma, o Vídeo 1 traz o movimento de um objeto com massa constante (pequeno carro em um trilho com um recipiente fechado acoplado com água), tracionado por um fio que passa por uma polia leve e é tensionado por um objeto preso em sua ponta. O Vídeo 2 apresenta o mesmo objeto se movendo com massa variável (o recipiente acoplado é furado, permitindo que água vaze, como é ilustrado na Figura 2). No Vídeo 3 o foco da filmagem está em um recipiente que coleta a água que escoa do recipiente, de forma semelhante ao que ocorre no segundo vídeo.

Tanto os dados obtidos do Vídeo 1 como do Vídeo 2 se referem às posições do carro em função do tempo, medidas em um referencial considerado inercial com origem fixada no laboratório, especificamente na posição inicial do carro, que parte do repouso em ambos os vídeos. Com os dados do Vídeo 1, foram inferidos os parâmetros das forças resistivas para cada um dos modelos contrastados. Já que os modelos contrastados consideram a massa do carro variável, a inferência dos parâmetros foi realizada por meio do ajuste desses modelos usando $R=0$ (vazão nula; massa constante), adequando-os ao evento do Vídeo 1. Com os dados coletados do Vídeo 2, foram construídas as evidências para se contrastar os modelos teóricos quando $R \neq 0$. O Vídeo 3 foi usado para se inferir o valor de $R$ no recipiente acoplado ao carro no segundo vídeo. Com ele, foram coletados dados da posição da superfície do líquido em função do tempo dentro de um béquer graduado, aos quais foi ajustado um

\footnotetext{
7 Os vídeos utilizados, assim como os dados coletados, estão disponibilizados em: http://www.if.ufrgs.br/gpef/modelagem/mas sa_variavel/. Acesso em 09 de abril de 2020.

- O carro e a roldana utilizados foram produzidos pela empresa

Pasco. Tratam-se de versões mais antigas dos modelos ME-

9430 e ME-9433, especificados em: https://www.pasco.com/ products/lab-apparatus/mechanics/carts-and-tracks/me-9430 e https://www.pasco.com/products/lab-supplies/pulleys/me-9433 Acesso em 02 de agosto de 2020.
}

polinômio de segundo grau, resultando em um coeficiente de determinação $r^{2}=0,99$. A interpretação do ajuste realizado evidencia que, assumindo a idealização de que a vazão diminui linearmente com o tempo, a vazão inicial foi de $(0,0404 \pm 0,0004) \mathrm{kg} / \mathrm{s}$ e a taxa de variação temporal dessa vazão foi de $(0,00051 \pm 0,00003) \mathrm{kg} / \mathrm{s}^{2}$. Ressalta-se que foi idealizado que a vazão do recipiente em repouso é igual à sua vazão quando acelerado no Vídeo 29

Para se estimar a incerteza dos dados coletados com o software Tracker, foram realizadas cinco videoanálises em cada um dos vídeos 1 e 2 . Por meio da análise do desvio padrão da média dos dados, estimou-se a incerteza das medidas em $1 \mathrm{~cm}$. As médias das posições coletadas a partir das cinco coletas de dados dos vídeos 1 e 2 foram analisados sete vezes com base no modelo teórico que estava sendo contrastado (os resultados dessas análises são apresentadas nas seções 5 e 6). Na próxima seção, são expostos os procedimentos realizados na análise desses dados, assim como os conduzidos para a construção das predições dos modelos contrastados.

\section{Análise de Dados e Construção de Predições: Soluções Analíticas e Modelagem Computacional com o Software Insight Maker}

As análises dos dados coletados com o Vídeo 1 e a contrastação de predições dos modelos com os dados coletados no Vídeo 2 foi realizada tanto por meio de soluções analíticas (para quatro dos modelos contrastados) com por meio de soluções numéricas. As soluções analíticas, apresentadas com detalhes em Material Suplementar, foram construídas se considerando a vazão do carro constante, ou seja, $R(t)=$ cte. Já as soluções numéricas foram desenvolvidas se considerando $R(t)=0,0404-0,00051 t$, como discutido na Seção 3 e utilizando o Insight Maker. O uso de duas soluções, analítica e numérica, possibilitou uma validação das predições construídas a partir dos modelos a serem contrastados. Ainda que tenham sido desenvolvidas a partir de pressupostos diferentes (considerando vazão constante em um caso e variável em outro), como a variação da vazão do carro era pequena (aproximadamente $1 \%$ por segundo), assumiu-se que as duas soluções, para serem validadas, deveriam resultar em predições consideravelmente similares.

O Insight Maker é um software online open-source de simulação computacional. Este aplicativo permite

\footnotetext{
9 Não está no escopo deste artigo discutir a influência da aceleração do recipiente na variação de pressão da água no seu interior. No entanto, considerando que a aceleração do carro no Vídeo 2 era da ordem de $0,05 \mathrm{~m} / \mathrm{s}^{2}$, pode-se estimar que a variação de pressão entre as extremidades do recipiente não é maior do que $5 \mathrm{~Pa}$, pressão equivalente à exercida por alguns poucos milímetros de água. Ou seja, a variação de pressão decorrente da aceleração do recipiente é muito pequena se comparada com a pressão exercida pela coluna de água compreendida no recipiente.
} 


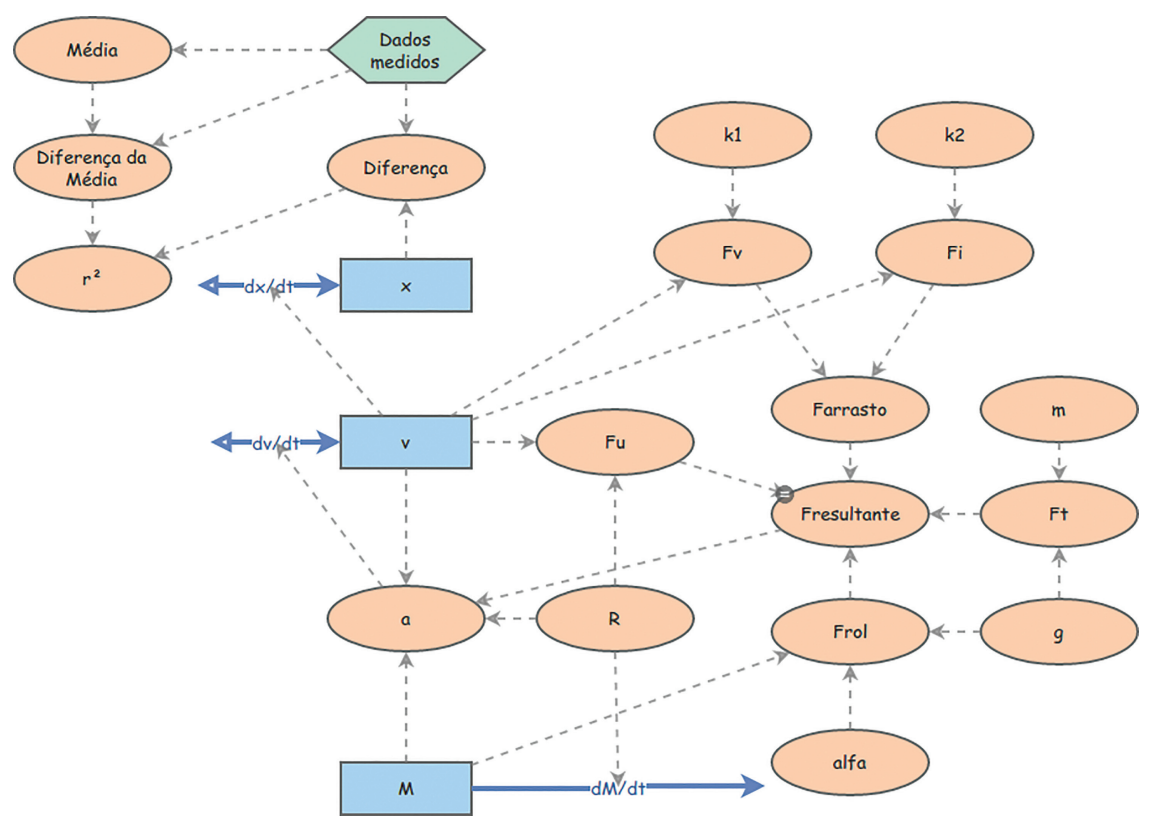

Figura 3: Diagrama de blocos do modelo teórico utilizado para representar o movimento de um carro com massa variável, construído com o software Insight Maker.

a modelagem de sistemas dinâmicos a partir de diagramação em blocos de elementos básicos (níveis, taxas e constantes) seguindo os princípios de sistemas de Forrester [26]. Funciona de modo similar ao software proprietário Stella ${ }^{10}$ para o qual é possível encontrar trabalhos a partir da década de 1990 que o utilizam no ensino de ciências [27. O programa realiza a integração numérica de modelos usando o método de Euler ou o método Runge-Kutta de quarta ordem, e possui ferramentas de otimização que permitem ajustes de parâmetros a dados inseridos nas simulações. Por funcionar por meio da diagramação gráfica de blocos, dispensa maiores conhecimentos de programação, sendo bastante útil em diversos contextos educacionais. A implementação no Insight Maker do modelo teórico mais completo contrastado neste artigo, que considera todas as forças discutidas na Seção 2 é realizada por meio da inserção de elementos gráficos representando grandezas e relações entre elas, resultando em um diagrama como o da Figura $3^{11}$ Explicações mais detalhadas desse processo podem ser consultadas no tutorial disponibilizado em 28].

No Insight Maker, os blocos do tipo "Stock" (nível), na forma de retângulos, são usados para se representar grandezas cuja variação é expressa por meio de setas do tipo "Flow" (fluxo/taxa) conectadas a eles. No esquema

${ }_{10}$ Disponível em: https://www.iseesystems.com/store/products/ stella-online.aspx Acesso em 02 de abril de 2020.

ii $\mathrm{O}$ arquivo com a simulação construída, que pode ser importado no Insight Maker, está disponível em: http://www.if. ufrgs.br/gpef/modelagem/massa_variavel/ A simulação pode ser acessada também em https://insightmaker.com/insight/201201/ Movimento-de-carro-com-massa-vari-vel Acesso em 06 de abril de 2020. da Figura 3 a caixa "Predição do Modelo", por exemplo, que é a variável que computa a predição da posição do carro em função do tempo, é uma grandeza desse tipo. Uma seta do tipo "Flow" (contínua) denominada "dx/dt" determina a sua taxa de variação temporal. A conexão de "dx/dt" e o nível "v", feita com uma linha tracejada, representa um "Link". Essa representação é usada para indicar que "dx/dt" é definida a partir de "v", que é a velocidade de $S$ em um referencial fixo no trilho. Essas relações precisam ser configuradas no modelo computacional por meio do preenchimento dos campos solicitados quando se é clicado no sinal "=" disponibilizado quando se passa o mouse sobre os elementos do diagrama (veja na parte superior à direta no bloco "Fresultante"). A Figura 4 a mostra o layout da janela em que são configuradas as propriedades de um elemento do diagrama.

Os blocos do tipo "Variable" ${ }^{12}$ na forma de elipses, são usados para se definir grandezas que são funções de outras grandezas do modelo ou que são constantes no evento investigado. O bloco "a", por exemplo, que representa a aceleração de $S$, é definido em termos da força resultante sobre $S$ (bloco "Fresultante"), da taxa de variação da massa de $S$ (bloco "Taxa M"), e da velocidade de $S$. Não está no escopo deste artigo explicar pormenores do funcionamento do Insight Maker, que podem ser consultados no site do aplicativo. Cabe destacar que os dados coletados com o Tracker foram

\footnotetext{
12 Da perspectiva da Modelagem Didático-Científica 6] 7], as grandezas representadas por blocos do tipo "Variable", apesar da forma como eles são intitulados, não são necessariamente variáveis. Parâmetros do sistema também podem ser inseridos nos modelos com blocos desse tipo.
} 


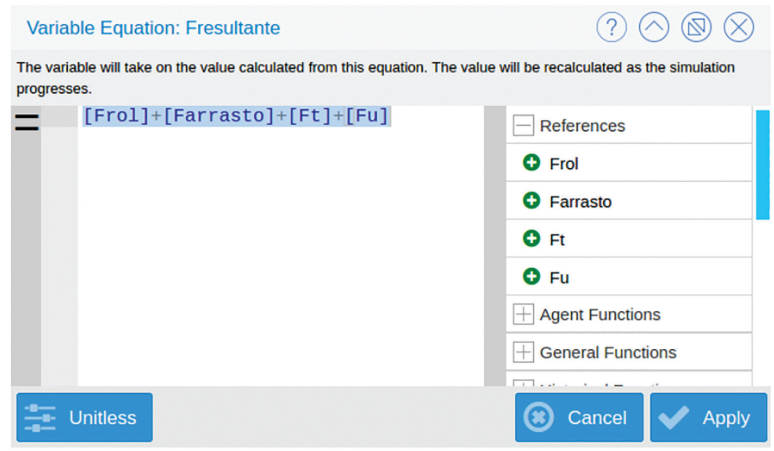

(a)

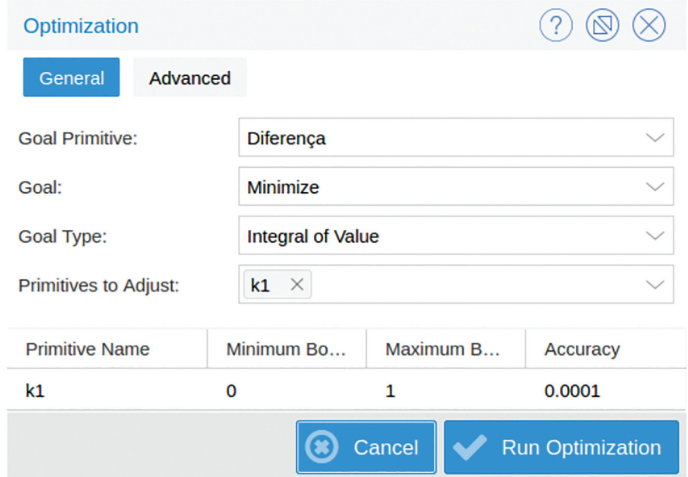

(b)

Figura 4: Layout da janela de configurações da elipse "Fresultante" no modelo construído (4.a) e da janela de ferramenta de otimização utilizada para a inferência dos parâmetros dos modelos (4.b).

inseridos na simulação no bloco "Dados medidos", que é uma grandeza do tipo "Converter", na forma de um hexágono, no Insight Maker. As soluções analíticas dos modelos, que serão exploradas na próxima seção, também foram inseridas na simulação como um bloco do tipo "Converter".

Os blocos do canto superior esquerdo da Figura 3 foram inseridos tanto para a realização dos ajustes de parâmetros realizados, que serão explicados no que segue, como para se avaliar a qualidade do ajuste do modelo aos dados, computado por um coeficiente de determinação $r^{2}$. Sinteticamente, o modelo computacional, a partir das considerações expostas na Seção 2 calcula a resultante das forças sobre o sistema $S$ e, a partir da aceleração inferida dessa força, computa a velocidade e a posição do carro representado.

Para todos os modelos contrastados, como já mencionado, os parâmetros das forças resistivas são inferidos por meio do ajustamento do modelo usando $R=0$ aos dados coletados do Vídeo 1. Para isso, foi utilizada a ferramenta "Optimization \& Goal Seek" disponível no menu "Tools". Como ilustrado na Figura 4 b, no campo "Goal Primitive", foi escolhida a grandeza "Diferença", que é definida como o valor absoluto da diferença entre a posição predita pelo modelo teórico e a posição medida com o Tracker. Em "Goal", foi escolhida a opção "Minimize", indicando que se desejava minimizar essa grandeza. Em "Goal Type", foi escolhido "Integral of Value", pois se desejava minimizar a integral desse valor. No campo "Primitive to Adjust", foram escolhidos os parâmetros dos modelos que foram ajustados, que eram diferentes para cada um deles. A precisão escolhida ("Accuracy" no Insight Maker) era de 0,0001 no processo de otimização. O valor inicial atribuído para as grandezas sempre era zero, e sempre é usado $g=9,79 \mathrm{~m} / \mathrm{s}^{2}$. O método de integração numérica utilizado foi Runge-Kutta de quarta ordem com passo 0,5 segundo.

De posse dos parâmetros relativos aos coeficientes de arrasto e de resistência ao rolamento, o modelo era integrado no software usando-se a função para a vazão do recipiente inferida dos dados do Vídeo 3. O parâmetro $r^{2}$, denominado coeficiente de determinação, foi utilizado para se avaliar a qualidade dos ajustes dos modelos teóricos aos dados coletados. Inferido da soma dos quadrados dos resíduos e da soma total dos quadrados dos modelos, esse coeficiente é interpretado como a porcentagem da variância dos dados experimentais que é explicada pelo modelo teórico contrastado. Portanto, quando esse coeficiente é próximo de 1 , infere-se que o modelo se adequa bem aos dados experimentais; valores próximos de 0 correspondem a modelos pouco ajustados aos dados. Uma discussão conceitual sobre o coeficiente de determinação pode ser consultada em 29. Na próxima seção, são apresentados os resultados obtidos com quatro diferentes modelos.

\section{Resultados: Uma análise do Domínio de Validade dos Modelos Teóricos Contrastados}

Nessa seção, são apresentadas a contrastação empírica de seis modelos teóricos. No primeiro deles (Subseção 5.1), despreza-se todas as forças resistivas. No segundo (Subseção 5.2), considera-se como força resistiva apenas a força de arrasto viscoso. No terceiro (Subseção 5.3), apenas a força de resistência ao rolamento é considerada como força resistiva. No quarto (Subseção 5.4), consideram-se duas forças: de arrasto viscoso com o ar e de resistência ao rolamento. No quinto (Subseção 5.5, consideração as forças de arrasto viscoso e inercial. No último (Subseção 5.6), são consideradas todas as forças resistivas discutidas na Seção 2 . Como o Insight Maker não fornece a incerteza dos parâmetros ajustados aos dados do Vídeo 1, não foi possível se estimar a incerteza das predições construídas com os modelos. Por isso, tomou-se como parâmetro para a comparação entre predições e dados experimentais a incerteza dos dados de posição coletados com o Tracker, estimada em $1 \mathrm{~cm}$. 


\subsection{Modelo teórico desprezando qualquer força resistiva}

No primeiro modelo teórico contrastado, a resultante das forças $\vec{F}_{\text {resx }}$ sobre $S$ na direção do seu movimento é dada por

$$
\vec{F}_{\text {res } x}=\vec{F}_{T}+\vec{F}_{\vec{u} x} .
$$

Usando a Equação 11, tem-se

$$
\ddot{x}=\frac{m}{M} g,
$$

ressaltando-se que, em todos os modelos tratados nessa seção, $M$ é uma função do tempo, ou seja, $M=M(t)$.

Nesta seção também são apresentadas as soluções analíticas de alguns dos modelos construídos considerando-se a vazão $R$ constante. As deduções dessas soluções são apresentadas em material suplementar ao artigo. No caso do modelo desta subseção, cuja solução é apresentada na Equação S3 do material suplementar, tem-se

$$
x(t)=\frac{m M_{0} g}{R^{2}}\left[\left(1-\frac{R}{M_{0}} t\right) \cdot \ln \left(1-\frac{R}{M_{0}} t\right)+\frac{R}{M_{0}} t\right] .
$$

No Insight Maker, foi possível se resolver a equação diferencial numericamente, considerando a vazão variável em função do tempo. Portanto, conforme a Equação (4), foi usado $R(t)=0,0404-0,00051 t$. Por isso, diferentemente do que é feito para expor as soluções analíticas dos modelos teóricos nesta seção, as análises computacionais são conduzidas se considerando a vazão variável.

A Figura [ $^{33}$ mostra que o modelo teórico que despreza forças resistivas não representa os dados experimentais satisfatoriamente, resultando em $r^{2}=0,58$.

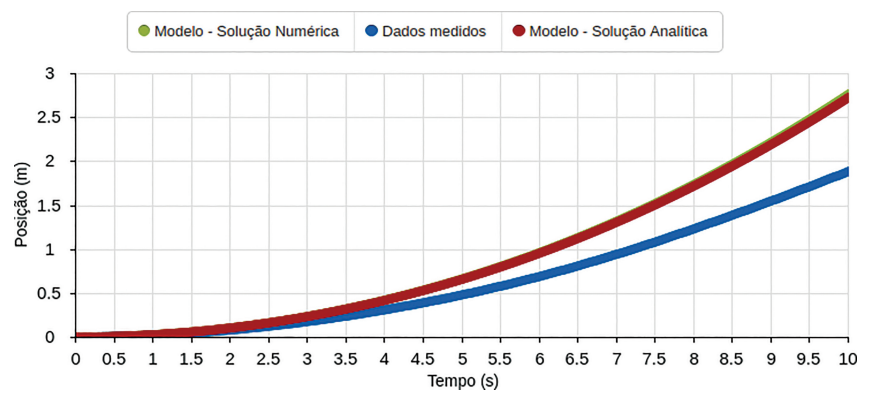

Figura 5: Dados medidos com o Vídeo 2 e predições do modelo teórico que despreza forças resistivas obtidas com soluções analítica (considerando vazão constante) e numérica. As soluções analítica e numérica se sobrepõem em significativa parcela do gráfico.

\footnotetext{
13 As aparentes linhas contínuas que representam os dados medidos em todos os gráficos deste artigo são, de fato, um conjunto grande de pontos coletados com o software Tracker. Como o Insight Maker não possibilita alterações no tamanho dos pontos representados, esses conjuntos aparentam constituir uma linha contínua.
}

As predições divergem mais do que $1 \mathrm{~cm}$, incerteza estimada para os dados medidos, a partir de 1,4 s do movimento. A diferença média durante todo o movimento foi de 27,2 cm. Para a construção de predições com a solução analítica ${ }^{14}$ foi usado $R=0,034 \mathrm{~kg} / \mathrm{s}$, que foi obtido de um ajuste linear aos dados coletados do Vídeo 3. Os resultados evidenciam que as forças resistivas sobre $S$ não são desprezíveis.

\subsection{Modelo teórico considerando como força resistiva apenas a força de arrasto viscoso}

Neste modelo, é considerado que

$$
\vec{F}_{r e s x}=\vec{F}_{T}+\vec{F}_{\vec{u} x}+\vec{F}_{v}
$$

Tem-se, portanto

$$
\ddot{x}=\frac{k_{1}}{M}\left(\frac{m g}{k_{1}}-\dot{x}\right) .
$$

A solução analítica dessa equação diferencial considerando $R=$ cte, que é exposta na Equação S8 do material suplementar, é

$$
x(t)=\frac{m g}{k_{1}}\left\{t+\frac{M_{0}}{k_{1}+R}\left[\left(1-\frac{R}{M_{0}} t\right)^{\frac{k_{1}}{R}+1}-1\right]\right\} .
$$

A Figura 6 mostra um melhor ajuste desse modelo aos dados experimentais. No entanto, as predições divergem dos dados experimentais em $1 \mathrm{~cm}$ já a partir de 1,7 $\mathrm{s}$, sendo que a média das diferenças entre as predições e os dados medidos é de $6,8 \mathrm{~cm}$. O coeficiente de determinação obtido foi de $r^{2}=0,95$. Foi usado $k_{1}=$ $0,321 \mathrm{~kg} / \mathrm{s}$, que, assim como foi feito em todas as análises expostas aqui, foi o valor inferido do ajuste do modelo usando $R=0$ aos dados coletados no Vídeo 1 . O Insight Maker não informa a incerteza dos parâmetros ajustados.

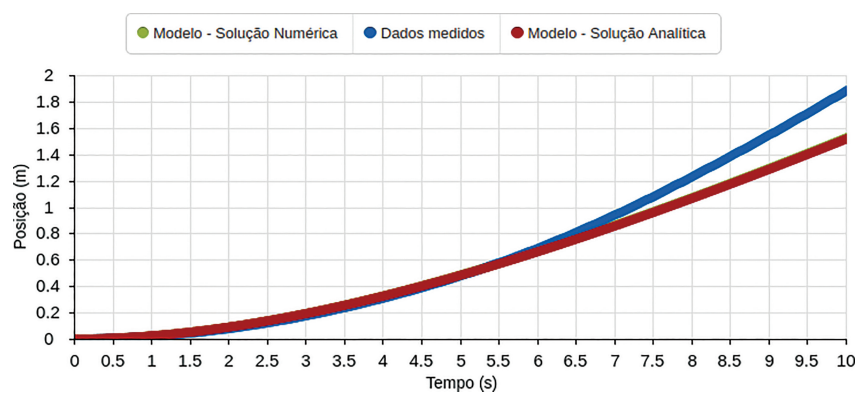

Figura 6: Dados medidos com o Vídeo 2 e predições do modelo teórico que considera apenas a força de arrasto viscoso como força resistiva obtidas com soluções analítica (considerando vazão constante) e numérica. As duas soluções se sobrepõem no gráfico.

\footnotetext{
14 As soluções analíticas foram inseridas no Insight Maker por meio de um bloco do tipo "Converter".
} 


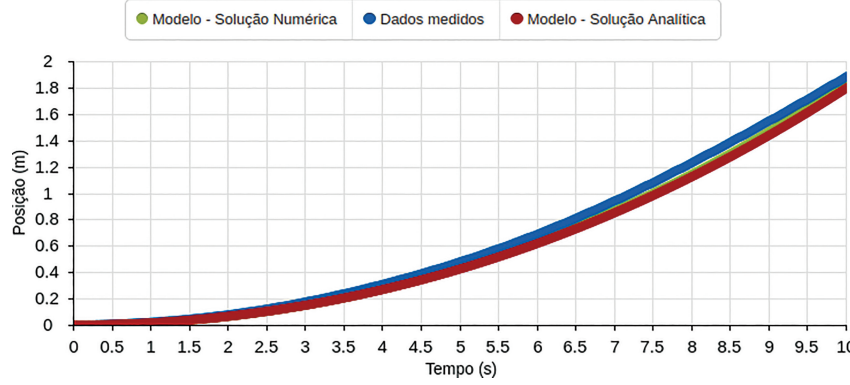

Figura 7: Dados medidos com o Vídeo 2 e predições do modelo teórico que considera apenas a força de resistência ao rolamento como força resistiva obtidas com soluções analítica (considerando vazão constante) e numérica. As duas soluções se sobrepõem no gráfico.

\subsection{Modelo teórico considerando como força resistiva apenas a força de resistência ao rolamento}

Considerando

$$
\vec{F}_{r e s x}=\vec{F}_{T}+\vec{F}_{\vec{u} x}+\vec{F}_{r o l},
$$

tem-se

$$
\ddot{x}=\left(\frac{m}{M}-\alpha\right) g .
$$

A solução analítica dessa equação diferencial considerando $R=$ cte (Equação S12 do material suplementar) é

$$
x(t)=\frac{m M_{0} g}{R^{2}}\left[\left(1-\frac{R}{M_{0}} t\right) \ln \left(1-\frac{R}{M_{0}} t\right)+\frac{R}{M_{0}} t\right]-\frac{1}{2} \alpha g t^{2} .
$$

O valor de $r^{2}=0,99$ evidencia que as predições desse modelo foram próximas aos dados experimentais. Foi identificada uma diferença média entre predições e dados experimentais de $3,2 \mathrm{~cm}$. A diferença, no entanto, é maior do que $1 \mathrm{~cm}$ a partir de $1,9 \mathrm{~s}$, voltando a ser menor do que esse valor no final do movimento, a partir de 9,8 s. A Figura 7 mostra que os resultados obtidos, evidenciando um bom ajuste em todo o intervalo de tempo investigado. $\mathrm{O}$ valor de $\alpha=1,87.10^{-3}$ usado foi inferido a partir do ajuste do modelo aos dados do Vídeo $1 \operatorname{com} R=0$ (vazão nula).

\subsection{Modelo teórico considerando como forças} resistivas as de resistência ao rolamento e de arrasto viscoso

Considerando

$$
\vec{F}_{r e s x}=\vec{F}_{T}+\vec{F}_{\vec{u} x}+\vec{F}_{r o l}+\vec{F}_{v},
$$

tem-se

$$
\ddot{x}=\left(\frac{m}{M}-\alpha\right) g+\frac{k_{1}}{M} .
$$

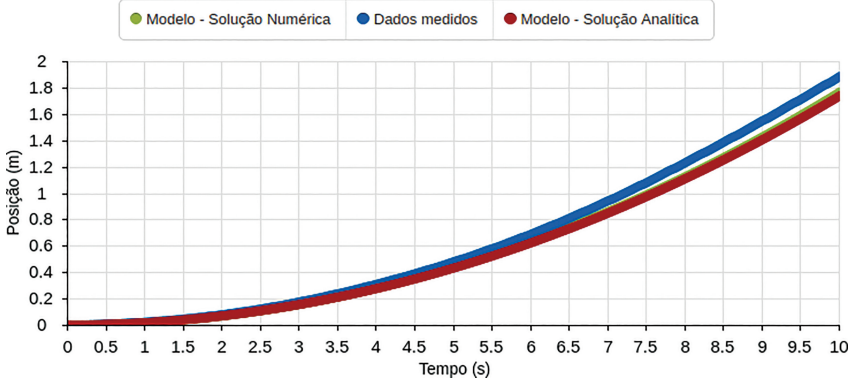

Figura 8: Dados medidos com o Vídeo 2 e predições do modelo teórico que considera força de resistência ao rolamento e força de arrasto viscoso obtidas com soluções analítica (considerando vazão constante) e numérica. As duas soluções se sobrepõem no gráfico.

A solução analítica dessa equação diferencial considerando $R=$ cte (Equação S19) é

$$
\begin{aligned}
x(t)= & \frac{M_{o} g}{\left(k_{1}+R\right)}\left(\frac{m}{k_{1}}+\frac{\alpha M_{0}}{R-k_{1}}\right) \\
& \times\left[\left(1-\frac{R}{M_{0}} t\right)^{\frac{k_{1}}{R}+1}-1\right] \\
& -\frac{\alpha g M_{0}^{2}}{2 \cdot R\left(R-k_{1}\right)}\left[\left(1-\frac{R}{M_{0}} t\right)^{2}-1\right]+\frac{m g}{k_{1}} t .
\end{aligned}
$$

A otimização realizada pelo Insight Maker depende do valor inicial atribuído aos parâmetros $\alpha$ e $k_{1}$. No resultado apresentado a seguir, optou-se por dividir o processo de ajuste para a identificação dos parâmetros $\alpha$ e $k_{1}$, realizada por meio do ajuste do modelo aos dados do Vídeo 1, em duas etapas. Primeiramente, foi inferido o valor do parâmetro $\alpha$ limitando o ajuste realizado aos cinco primeiros segundos do movimento do carro com massa constante, pois, como a velocidade do carro é menor nesse intervalo, a força de arrasto deve ter pouco efeito. Nesse ajuste, o valor de $k_{1}$ foi mantido igual a zero. Em seguida, mantendo $\alpha$ fixo com o valor encontrado no primeiro procedimento, foi realizado um novo ajuste para todo o movimento otimizando o valor de $k_{1}$. O software identificou os seguintes valores para os parâmetros: $k_{1}=0,064 \mathrm{~kg} / \mathrm{s}$ e $\alpha=1,56 \cdot 10^{-3}$. Os ajustes obtidos, que resultaram em um $r^{2}=0,98$, estão sintetizados na Figura 8 Os resultados evidenciam uma boa aderência do modelo aos dados experimentais (diferença entre predições e dados experimentais menor que $1 \mathrm{~cm}$ ) até $2,4 \mathrm{~s}$. A diferença média entre predições e dados empíricos foi de $4,4 \mathrm{~cm}$.

5.5. Modelo teórico considerando como forças resistivas apenas a força de arrasto viscoso e a força de arrasto inercial

Considerando

$$
\vec{F}_{r e s x}=\vec{F}_{T}+\vec{F}_{\vec{u} x}+\vec{F}_{v}+\vec{F}_{i},
$$




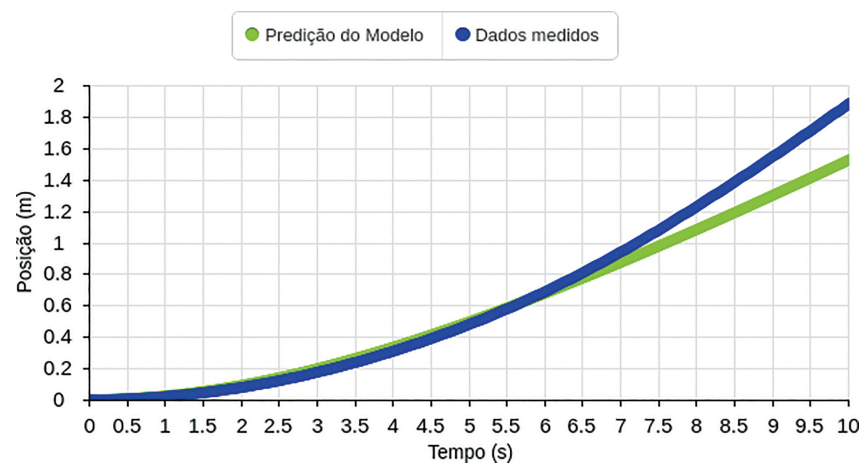

Figura 9: Dados medidos com o Vídeo 3 e predições do modelo teórico que considera as forças de arrasto viscoso e de arrasto inercial como forças resistivas.

tem-se

$$
\ddot{x}=\frac{1}{M}\left(m g-k_{1} v-k_{2}|v| v\right) .
$$

Não foi encontrada (tanto na literatura quanto pelos métodos testados pelos autores) solução analítica para este modelo, evidenciando as potencialidades da integração numérica proporcionada pelo Insight Maker. Foram identificados diversos ajustes desse modelo teórico com qualidade semelhante para representar os dados experimentais se atribuindo diferentes valores iniciais para os parâmetros ajustados. A solução considerada mais adequada para esse modelo foi obtida em um processo de duas etapas em que, primeiramente, foi inferido o valor de $k_{1}$ limitando o ajuste para os cinco primeiros segundos do movimento do carro com massa constante, quando a sua velocidade é menor e, portanto, o efeito da força de arrasto inercial deve ser desprezível frente a de arrasto viscoso. Em seguida, foi atribuído o valor obtido nesse primeiro ajuste como valor inicial para $k_{1}$ e realizado um novo ajuste para todo o movimento, otimizando os dois coeficientes. Foram obtidos os valores $k_{1}=0,269 \mathrm{~kg} / \mathrm{s}$ e $k_{2}=0,385 \mathrm{~kg} / \mathrm{m}$. Usando-se esses parâmetros e a função que representa a vazão do recipiente em função do tempo, foram obtidos os resultados expostos na Figura 9 . em que $r^{2}=0,70$. Evidencia-se uma boa aderência do modelo aos dados até $1,8 \mathrm{~s}$, sendo que a média da diferença entre as predições e os dados empíricos foi de $7,2 \mathrm{~cm}$. Portanto, considerar as duas forças de arrasto, utilizando o procedimento proposto aqui, não implica significativa maior explicação da variância dos dados experimentais.

\subsection{Modelo teórico considerando forças de resistência ao rolamento, de arrasto viscoso e de arrasto inercial}

Neste último modelo teórico contrastado, são consideradas todas as forças propostas na Seção 2 Logo

$$
\vec{F}_{r e s x}=\vec{F}_{T}+\vec{F}_{\vec{u} x}+\vec{F}_{v}+\vec{F}_{i}+\vec{F}_{r o l} .
$$

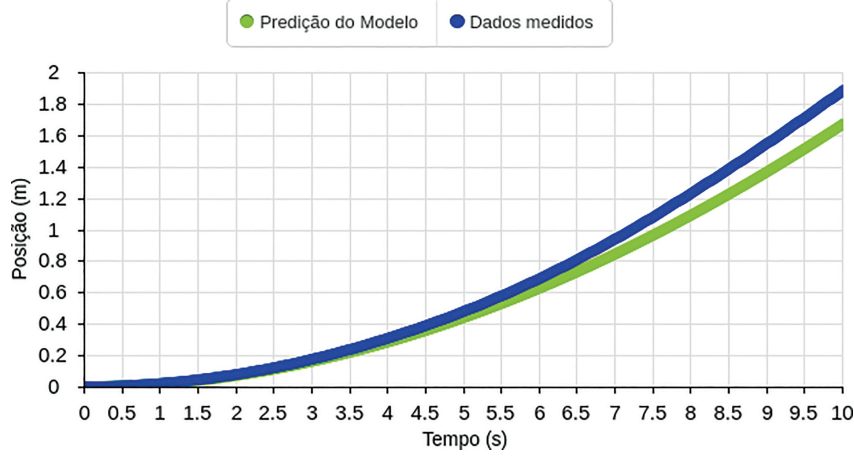

Figura 10: Dados medidos com o Vídeo 3 e predições do modelo teórico que considera as forças de resistência ao rolamento, de arrasto viscoso e de arrasto inercial como forças resistivas.

\section{Portanto}

$$
\ddot{x}=\frac{1}{M}\left(m g-k_{1} v-k_{2}|v| v-\alpha M g\right) .
$$

Também não foi encontrada solução analítica para este modelo. De modo semelhante ao realizado nos ajustes anteriores, optou-se por proceder a inferência dos parâmetros em partes. Primeiro, atribuiu-se o valor zero para todos os parâmetros do modelo. Usamos a ferramenta de otimização para os três primeiros segundos do Vídeo 1 (quando a velocidade do carro é pequena, as forças de arrasto são pequenas), foi realizada a inferência de $\alpha$. Em seguida, inferiu-se o valor de $k_{1}$ se atribuindo o valor zero para $k_{2}$ e mantendo fixo o valor de $\alpha$ identificado no primeiro ajuste, procedendo-se, então, o ajuste do modelo para os sete primeiros segundos do vídeo. Por fim, inferiu-se o valor de $k_{2}$ ajustando o modelo para todo o movimento gravado mantendo fixo os valores de $\alpha$ e $k_{1}$ identificados nas duas primeiras etapas. Com isso, os parâmetros inferidos foram: $\alpha=1,37.10^{-3}$, $k_{1}=0,1128 \mathrm{~kg} / \mathrm{s}$ e $k_{2}=0 \mathrm{~kg} / \mathrm{m}$. Esse resultado mostra que, frente ao procedimento realizado, a força de arrasto inercial não possibilitou um melhor ajuste. A Figura 10 representa o resultado dessa contrastação, com $r^{2}=0,97$. Os resultados mostram uma boa aderência do modelo aos dados até aproximadamente $2,9 \mathrm{~s}$, quando o modelo passa a divergir mais do que $1 \mathrm{~cm}$ dos dados experimentais. No entanto, a diferença média entre as predições e os dados experimentais foi de $5,8 \mathrm{~cm}$ em todo o movimento, maior do que o obtido no modelo da Subseção 5.3. por exemplo. Cabe destacar que, ainda que a otimização realizada tenha resultado em um coeficiente de arrasto inercial igual a zero, a análise realizada aqui não se reduz ao resultado exposto na Subseção 5.4 porque os procedimentos para a inferência dos parâmetros dos modelos foram realizados de forma diferente em função das características desses modelos.

Destaca-se que outros procedimentos para a identificação dos parâmetros ajustados foram testados, mas em nenhum deles foi obtido um ajuste de qualidade 
consideravelmente melhor do que a alcançada com o procedimento apresentado aqui.

\subsection{Comparação entre os resultados dos mode- los investigados}

A comparação entre as soluções numéricas (considerando a vazão variável) e analíticas (considerando a vazão constante), quando foi possível, constituiu em um indício da validação das predições construídas com base nos modelos teóricos desenvolvidos. As diferenças entre essas soluções, representadas nas figuras $5,6,7 \mathrm{e}, 8$ não passou de $3,4 \mathrm{~cm}$ para nenhum dos modelos investigados, mostrando que a variação da vazão do carro teve influência desprezível em seu movimento.

Como conclusão das análises realizadas, pode-se inferir que, frente aos procedimentos realizados, o modelo teórico que melhor representou os dados experimentais é o exposto na Subseção 5.3 que considera como força resistiva apenas a força de resistência ao rolamento. A Tabela 1 sintetiza os resultados, e a Figura 11 representa as predições dos seis modelos investigados.

Tabela 1: Síntese das análises realizadas. Na primeira coluna, são registrados os modelos teóricos investigados; na segunda, o tempo transcorrido para que ocorresse uma divergência de 1 $\mathrm{cm}$, incerteza estimada dos dados medidos, entre as predições e os dados experimentais; na terceira, a divergência média entre as predições e os dados experimentais durante os $10 \mathrm{~s}$ de movimento investigados.

\begin{tabular}{|c|c|c|}
\hline Modelo Teórico... & $\begin{array}{c}\text { Tempo } \\
\text { transcorrido } \\
\text { para } \\
\text { divergência } \\
\text { de } 1 \mathrm{~cm}(\mathrm{~s})\end{array}$ & $\begin{array}{l}\text { Divergência } \\
\text { média } \\
(\mathrm{cm})\end{array}$ \\
\hline $\begin{array}{l}\text {...desprezando qualquer } \\
\text { força resistiva }\end{array}$ & 1,4 & 27,2 \\
\hline $\begin{array}{l}\text {...considerando como força } \\
\text { resistiva apenas a força de } \\
\text { arrasto viscoso }\end{array}$ & 1,7 & 6,8 \\
\hline $\begin{array}{l}\text {...considerando como força } \\
\text { resistiva apenas a força de } \\
\text { resistência ao rolamento }\end{array}$ & 1,9 & 3,2 \\
\hline $\begin{array}{l}\text {...considerando como forças } \\
\text { resistivas as de resistência } \\
\text { ao rolamento e de arrasto } \\
\text { viscoso }\end{array}$ & 2,4 & 4,4 \\
\hline $\begin{array}{l}\text {...considerando como forças } \\
\text { resistivas apenas a força de } \\
\text { arrasto viscoso e a força de } \\
\text { arrasto inercial }\end{array}$ & 1,8 & 7,2 \\
\hline $\begin{array}{l}\text {...considerando forças de } \\
\text { resistência ao rolamento, } \\
\text { de arrasto viscoso e de } \\
\text { arrasto inercial }\end{array}$ & 2,9 & 5,8 \\
\hline
\end{tabular}

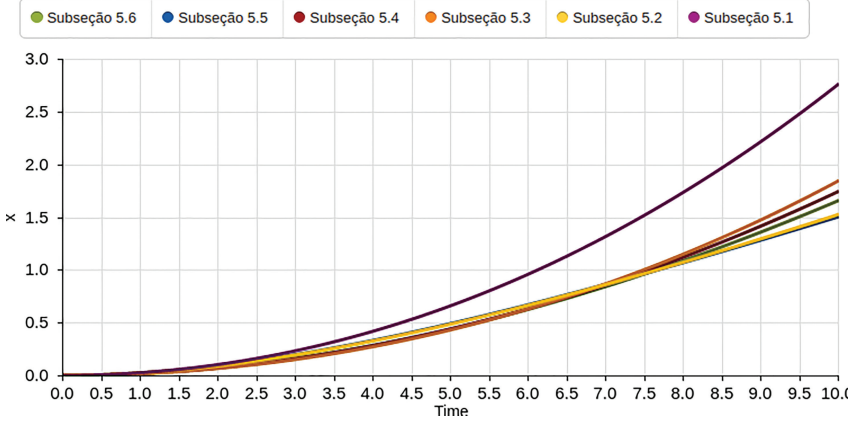

Figura 11: Soluções numéricas dos modelos teóricos investiga$\operatorname{dos} 16$

\section{O que podemos concluir? Poderíamos ter um ajuste melhor? Quais são as implicações dessa discussão para o ensino de Física?}

A análise dos dados coletados mostrou que, com os procedimentos escolhidos, o modelo teórico que melhor representou o evento investigado é o que considera apenas resistência ao rolamento, desprezando forças de arrasto com o ar. O bom ajuste alcançado com esse modelo (Figura 7) fornece apoio empírico para a hipótese de que a força de arrasto com o ar é desprezível no evento investigado quando comparada com as outras forças que agem no sistema $S$, assim como para as outras hipóteses registradas na construção do modelo expostas na Seção 2 Além disso, apesar de as soluções analíticas terem sido construídas se considerando a taxa de variação da massa do sistema constante, o que não foi considerado na solução numérica, a comparação entre soluções analíticas e numéricas possibilitou uma validação das predições construídas, dando credibilidade às soluções obtidas.

Neste ponto do artigo, é natural que o leitor se pergunte: Mas como um modelo mais completo, que possui menos idealizações, não foi mais preciso do que um modelo mais idealizado? Antes de se abordar essa questão, é preciso destacar que, evidentemente, existem forças de arrasto com o ar no evento real investigado. É preciso destacar também que um ajuste melhor do que o exposto na Figura 10, por exemplo, é facilmente obtido por meio de outros procedimentos diferentes dos utilizados na investigação. O ajuste apresentado na Figura 12, realizado a partir do modelo teórico exposto na Seção 5.6. o mais completo entre os construídos, tem qualidade superior ao proposto na Figura 10. Nesse caso, desprezando-se os dados do Vídeo 1, a otimização foi realizada por meio do ajuste do modelo diretamente aos dados da posição em função do tempo do carro com

\footnotetext{
16 Este gráfico foi construído por meio da ferramenta "Compare Results", do Insight Maker. Nessa ferramenta, não é possível se editar os eixos dos gráficos construído. Por isso, foi mantido " $\mathrm{x}$ " no eixo das ordenadas e o termo em inglês "Time" no eixo das abscissas.
} 


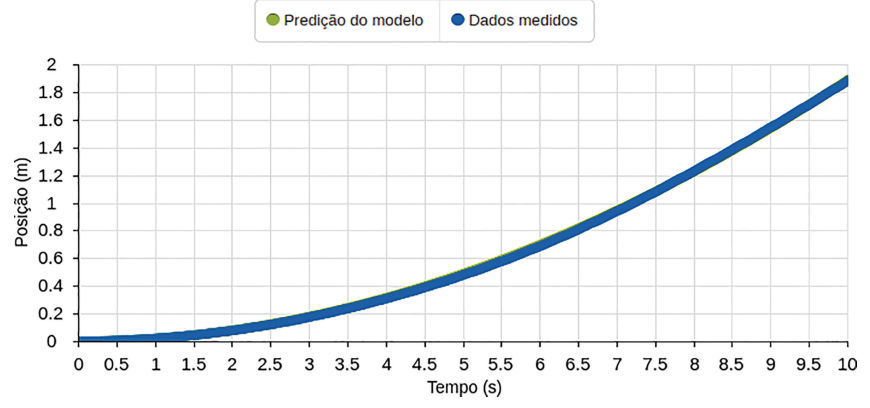

Figura 12: Ajuste do modelo teórico da Seção 5.6 aos dados do Vídeo 2. As predições e os dados medidos se sobrepõem.

massa variável coletados com o Vídeo $2\left(\alpha=9,5.10^{-4}\right.$, $k_{1}=0,073 \mathrm{~kg} / \mathrm{s}$ e $\left.k_{2}=0,206 \mathrm{~kg} / \mathrm{m}\right)$. O coeficiente de determinação do ajuste foi $r^{2}=0,99$.

Os resultados expostos na Figura 12, em um contexto didático, poderiam levar aos seguintes questionamentos: Esse não é o melhor procedimento para se representar o evento investigado? Como um cientista precederia frente a uma situação como essa? A resposta a essa pergunta, que pode promover importantes discussões sobre o fazer científico em uma aula de Física, passa por uma reflexão sobre os critérios de avaliação de modelos teóricos. Como destacado em Silveira e Ostermann [22, e demonstrado em [30], sempre é possível se identificar um polinômio com grau $m=(n-1)$, onde $n$ é o número de pontos experimentais, que passa exatamente por todos os pontos. Além disso, existem infinitas outras funções, com $n$ parâmetros a serem determinados a partir dos resultados experimentais, que se ajustam perfeitamente aos dados. Portanto, se o procedimento utilizado para se contrastar um modelo for reduzido a uma avaliação da qualidade do seu ajuste aos dados experimentais, um modelo com mais parâmetros a serem ajustados será privilegiado quando comparado com um com menos parâmetros.

Considerando o exposto, ainda que se tenha identificado um excelente ajuste aos dados com o procedimento realizado para a construção da Figura 12 (as curvas se sobrepõem), conceitualmente ele representa uma contrastação empírica mais frágil do que as exploradas na seção anterior. Isso porque os parâmetros usados são completamente definidos pelos dados experimentais, ou seja, a curva ajustada é definida pelos próprios dados experimentais. Já nos procedimentos da seção anterior, os parâmetros utilizados são inferidos a partir da análise de outro evento, o movimento do carro com massa constante do Vídeo 1. Em suma, os procedimentos utilizados na seção anterior, usando palavras de Popper [31], são mais audazes; eles são mais expostos à refutação do que os utilizados na construção da Figura 12.

Poder-se-ia argumentar, então, que existem métodos estatísticos para se definir até que ponto é válido se aumentar a ordem de um polinômio quando se busca representar dados empíricos. A esse argumento se pode acrescentar que tais métodos, como o uso do quiquadrado, envolvem um certo grau de arbitrariedade, ainda que envolvam elementos lógicos. São construções humanas, desenvolvidas a partir da criatividade de cientistas que buscam tornar objetivos os procedimentos realizados em laboratório. Inclusive, não são métodos universais, utilizados igualmente por todos os cientistas, pois variações de tais métodos são contextualmente desenvolvidas pelos pesquisadores, dependendo dos seus interesses. Para mais informações, consulte [30].

Voltando à pergunta do início desta seção, em que se questionava como um modelo científico mais completo, que possui menos idealizações, não foi mais preciso do que um modelo mais idealizado, pode-se argumentar que, de fato, na investigação realizada, o modelo teórico mais completo pode sim promover predições mais precisas, como exposto na Figura 12 No entanto, o processo de contrastação empírica é bastante mais complicado do que a avaliação da acurácia das predições de um modelo teórico. A qualidade do ajuste de um modelo teórico a um conjunto de dados, isoladamente, não é um critério único e absoluto para a validação desses modelos.

Pautando-se no exposto aqui, professores podem, a partir de uma situação experimental em uma aula de Física, além de conduzir atividades para se ensinar conceitos de Física como de referencial, força e momentum, discutir sobre a natureza do conhecimento científico. Entre outras coisas, pode-se, a partir da abordagem dessa investigação em sala de aula: $i$. destacar que experimentos não promovem a prova ou refutação definitiva de um modelo científico, mas possibilitam a construção de apoio empírico para o cientista que deseja avaliar o domínio de validade dos modelos científicos; $i$. evidenciar o caráter representacional do conhecimento científico, mostrando que os modelos teóricos explorados possuem domínio de validade relacionado com as idealizações que são consideradas e que eles podem ser expandidos para representarem outros eventos reais; e iii. debater sobre o caráter essencialmente humano do processo de modelagem científica e, consequentemente, da construção do conhecimento científico, ressaltando que a escolha das idealizações consideradas envolve tomada de decisão pautada por, além de conhecimentos científicos, objetivos e crenças sobre o evento investigado, e que os procedimentos estabelecidos na contrastação desses modelos não são algorítmicos, envolvendo criatividade e inspiração.

\section{Considerações Finais}

Os modelos teóricos contrastados neste artigo possibilitam a construção de uma maior compreensão sobre o movimento de corpos com massa variável, como foguetes, gotas de chuva, esteiras rolantes ou um caminhão regador. Frequentemente discutidos de forma teórica 
em artigos [e.g., [13 17]], esses modelos não costumam ser explorados em atividades didáticas experimentais ${ }^{17}$ Os resultados deste artigo evidenciaram que a variação de massa dos sistemas é um aspecto essencial para se representar esses eventos, e que forças resistivas precisam ser consideradas para representá-los. Além disso, a forma como o uso dos software livres Tracker e Insight Maker foram utilizados mostra como recursos computacionais podem, para além de ilustrar eventos físicos, possibilitar a construção de soluções que não seriam possíveis em contextos didáticos sem eles.

Destaca-se aqui que, mais do que construir uma conclusão sobre quais forças resistivas são ou não importantes no evento investigado, o objetivo deste artigo é expor algo talvez até mais complexo do que os próprios modelos contrastados e os procedimentos utilizados, que é a explicitação de reflexões pautadas pela epistemologia da ciência a partir de uma situação experimental. Uma das mais importantes contribuições deste artigo para o ensino de Física é propor uma discussão sobre como um problema sobre a contrastação empírica de modelos científicos possibilita debates sobre a natureza da ciência, em particular sobre o caráter representacional do conhecimento científico e sobre o papel da experimentação na fazer científico. Como destacado na introdução, ainda que debates sobre as ideias de grandes epistemólogos promovidos em disciplinas específicas sobre filosofia da ciência sejam muito importantes, é essencial que os estudantes vivenciem também situações em que debates sobre a natureza da ciência sejam realizados em situação, ou seja, em atividades em que estejam resolvendo problemas didático-científicos de Física, possibilitando uma vinculação da filosofia da ciência aos conteúdos científicos. Entendendo que a difusão dessas situações são fundamentais para a área de ensino de ciências, tem-se como perspectiva futura contribuir para a área com mais debates sobre aspectos da modelagem científica em problemas de Física.

\section{Agradecimentos}

Agradecemos às professoras Eliane Angela Veit e Sandra Denise Prado e ao professor Fernando Lang da Silveira pela leitura crÃtica do artigo. Ives Solano Araujo agradece ao apoio recebido pelo $\mathrm{CNPq}$ na forma de Bolsa de Produtividade nível 2.

\section{Material suplementar}

O seguinte material suplementar está disponível online: Material suplementar

\footnotetext{
17 Não identificamos na literatura da área de ensino de Física artigos com contrastações experimentais de modelos teóricos que representam o movimento de corpos com massa variável.
}

\section{Referências}

[1] M.A. Moreira e F. Ostermann, Caderno Catarinense de Ensino de Física 10, 108 (1993).

[2] D. Hodson, Studies in Science Education 12, 25 (1985).

[3] A.M.P. Carvalho, Calor e Temperatura: um ensino por investigação (Livraria da Física, São Paulo, 2014).

[4] C.T.W. Rosa, A Metacognição e as atividades experimentais no ensino de Física. Tese de Doutorado, Universidade Federal de Santa Catarina, Santa Catarina (2012).

[5] S. Alllie, A. Buffler, B. Campbell, F. Lubben, D. Evangelinos, D. Psillos e O. Valassiades, The Physics Teacher 41, 394 (2003).

[6] P.S. Camargo Filho, C.E. Laburú e M.A. Barros, Ciência \& Educação 21, 817 (2015).

[7] R.V. Brandão, I.S. Araujo e E.A. Veit, Caderno Brasileiro de Ensino de Física 28, 507 (2011).

[8] L.A. Heidemann, I.S. Araujo e E.A. Veit, Caderno Brasileiro de Ensino de Física 33, 3 (2016).

[9] M. Bunge, Teoria e Realidade (Editora Perspectiva, São Paulo, 1974).

[10] G. Vergnaud, Human development 52, 83 (2009).

[11] R.R. Campomanes, L.A. Heidemann e E.A. Veit, Revista Brasileira de Ensino de Física 42, e20190076 (2020).

[12] T. Amiel, em: Recursos Educacionais Abertos: práticas colaborativas e políticas públicas, Salvador, editado por B. Santana, C. Rossini e N.D.L. Pretto (Edufba, Salvador, 2012), p. 246.

[13] D.R. Silva e P. Peixoto, Revista Brasileira de Ensino de Física 38, e2317 (2016).

[14] M.T. Thomaz e E.V.C. Silva, Revista Brasileira de Ensino de Física 41, e20180344 (2019).

[15] A.V. Kraff, G.G. Vásquez, R.R. Mijangos e J.A. Heredia-Cancino, Revista Mexicana de Física 61, 6 (2015).

[16] M.S. Tiersten, American Journal of Physics 37, 82 (1969).

[17] K. Nakayama, European Journal of Physics 39, 055002 (2018).

[18] F.L. Silveira, Revista de Enseñanza de la Física 10, 29 (1995).

[19] F. L. Silveira, Revista Brasileira de Ensino de Física 33, 1304 (2011).

[20] A.V. Andrade-Neto, J.A. Cruz, M.S.R. Miltão e E.S. Ferreira, Revista Brasileira de Ensino de Física 35, 1 (2013).

[21] C.E. Aguiar e G. Rubini, Revista Brasileira de Ensino de Fisica 26, 297 (2004).

[22] F. L. da Silveira e F. Ostermann, Caderno Brasileiro de Ensino de Física 19, 7 (2002).

[23] D. Mayo, Philosophy of Science 67, S193-S207 (2000).

[24] L.K. Wee, C. Chew, G.H. Goh, S. Tan e T.L. Lee, Physics Education 47, 448 (2012).

[25] L.A. Heidemann, I.S. Araujo e E.A. Veit, Caderno Brasileiro de Ensino de Física 29, 965 (2012).

[26] S. Fortmann-Roe, Simulation Modelling Practice and Theory 47, 28 (2014) 
[27] A.C.K. Santos, Y. Cho, I.S. Araujo e G.P. Gonçalves, Caderno Catarinense de Ensino de Física 17, 81 (2000).

[28] M. Lauschner, L.A. Heidemann e E.A. Veit, Tutorial para o uso do software Insight Maker, disponível em: https://lief.if.ufrgs.br/pub/cref/rd/n08_Lauschner/ arquivos/tutorial_PDF.pdf

[29] O Raciocínio para o $R^{2}$, disponível em: https://pt.khana cademy.org/math/ap-statistics/bivariate-data-ap/asses sing-fit-least-squares-regression/a/r-squared-intuition

[30] C.H. Asano e E. Colli, Cálculo Numérico: Fundamentos e Aplicações (IME-USP, São Paulo, 2009).

[31] K. Popper, Conjecturas e Refutações (Editora da UnB, Brasília, 2008). 